\title{
Kinetics and mechanism of the aminolysis of diaryl carbonates
}

\author{
Enrique A. Castro,* Claudia Soto, Bárbara Vásquez, and José G. Santos* \\ Facultad de Química, Pontificia Universidad Católica de Chile, Casilla 306, Santiago 6094411, \\ Chile \\ E-mail: jgsantos@uc.cl
}

\section{Dedicated to Professor Dr Nouria Al-Awadi}

\begin{abstract}
The reactions of secondary alicyclic (SA) amines with 4-nitrophenyl 2,4-dinitrophenyl carbonate (4) and bis(2,4-dinitrophenyl) carbonate (5) are subjected to a kinetic investigation in $44 \mathrm{wt} \%$ ethanol-water, at $25.0^{\circ} \mathrm{C}$, ionic strength $0.2 \mathrm{M}$. The reactions are examined by monitoring spectrophotometrically the appearance of 2,4-dinitrophenoxide. Under conditions of excess amine, pseudo-first-order rate coefficients $\left(k_{\mathrm{obsd}}\right)$ are found. Plots of kobsd against free amine concentration at constant $\mathrm{pH}$ are linear with $k_{N}$ as slope. The Brønsted-type plots (log $k_{N}$ vs amine $\mathrm{p} K_{\mathrm{a}}$ ) obtained are also linear with slopes 0.51 and 0.48 for the aminolysis of 4 and 5 , respectively. These slope values are in accordance with concerted (one step) mechanisms. The absence of a Brønsted break at the predicted $\mathrm{p} K_{\mathrm{a}}$ for hypothetical stepwise mechanisms confirms the concerted nature of these reactions.
\end{abstract}

Keywords: Diaryl carbonates, aminolysis, kinetics, mechanism

\section{Introduction}

Although the kinetics and mechanisms of the aminolysis of dialkyl and alkyl aryl carbonates are well documented, ${ }^{1,2}$ less is known on the mechanisms of diaryl carbonates. ${ }^{3-7}$ For the former carbonates a zwitterionic tetrahedral intermediate on the reaction path has been proposed (stepwise mechanism). ${ }^{1,2}$ On the other hand, for the aminolysis of diaryl carbonates, both stepwise and concerted (one step) mechanisms have been reported, depending on the leaving groups involved. ${ }^{3-7}$ Generally, for very good leaving groups the concerted mechanism takes place. We have recently studied the kinetics of the reactions of quinuclidines with phenyl, 4methylphenyl, and 4-chlorophenyl 2,4-dinitrophenyl carbonates (1, 2, and 3, respectively). ${ }^{5}$ Also investigated have been the reactions of secondary alicyclic (SA) amines and anilines with 
carbonates 2 and 3., ${ }^{6,7}$ All these reactions have been shown to obey concerted (one step) mechanisms.

With the aim of extending our kinetic investigation on the aminolysis of diaryl carbonates, we have now studied the mechanism of the reactions of SA amines with 4-nitrophenyl 2,4dinitrophenyl carbonate (4) and bis(2,4-dinitrophenyl) carbonate (5). Specific goals are to evaluate the effect of two good leaving groups in the carbonate and also the nature of the amine on the kinetics and mechanism. This will be achieved by comparison of the title reaction with the aminolyses (quinuclidines and anilines) of the same and similar carbonates.
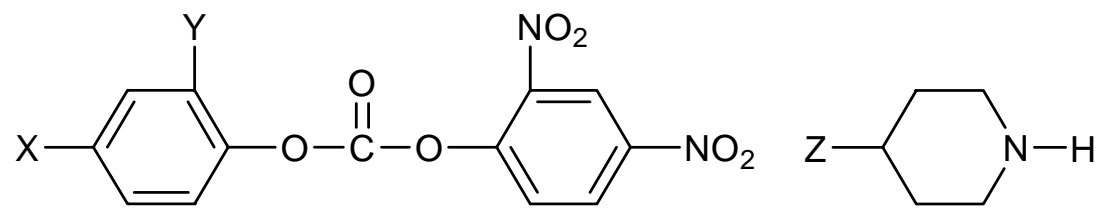

$$
\begin{aligned}
& \mathbf{1}(\mathrm{X}=\mathrm{Y}=\mathrm{H}) \\
& \mathbf{2}\left(\mathrm{X}=\mathrm{CH}_{3} ; \mathrm{Y}=\mathrm{H}\right) \\
& \mathbf{3}(\mathrm{X}=\mathrm{Cl} ; \mathrm{Y}=\mathrm{H}) \\
& \mathbf{4}\left(\mathrm{X}=\mathrm{NO}_{2} ; \mathrm{Y}=\mathrm{H}\right) \\
& \mathbf{5}\left(\mathrm{X}=\mathrm{Y}=\mathrm{NO}_{2}\right)
\end{aligned}
$$

SA amines

\section{Results and Discussion}

The reactions investigated in this work are governed by the rate law given by Eqs 1 and 2, where $\mathrm{P}, \mathrm{S}$ and $\mathrm{NH}$ represent a product, the substrate and the free amine, respectively, and $k_{0}$ and $k_{\mathrm{N}}$ are the rate coefficients for hydrolysis and aminolysis of the substrates, respectively.

$$
\begin{aligned}
& \frac{\mathrm{d}[\mathrm{P}]}{\mathrm{dt}}=k_{\mathrm{obsd}}[\mathrm{S}] \\
& k_{\mathrm{obsd}}=k_{0}+k_{\mathrm{N}}[\mathrm{NH}]
\end{aligned}
$$

The values of $k_{\mathrm{N}}$ for all the reactions were determined as the slope of linear plots of $k_{\mathrm{obsd}} \mathrm{Vs}[\mathrm{NH}]$ and were found to be $\mathrm{pH}$ independent.

The values of $k_{\text {obsd }}$ for the reactions of SA amines with carbonates $\mathbf{4}$ and $\mathbf{5}$ are shown in Tables 1 and 2 , respectively. 
Table 1. Experimental conditions and $k_{\text {obsd }}$ values for the aminolysis of 4-nitrophenyl 2,4dinitrophenyl carbonate (4) ${ }^{\mathrm{a}}$

\begin{tabular}{|c|c|c|c|c|c|}
\hline Amine & pH & $\boldsymbol{F}_{\mathbf{N}}^{\mathbf{b}}$ & $103[N]_{\text {tot }} / \mathbf{M}^{\mathrm{c}}$ & $103 k_{\text {obsd }} / \mathrm{s}^{-1}$ & $\begin{array}{l}\text { No.of } \\
\text { runs }\end{array}$ \\
\hline \multirow[t]{3}{*}{ piperidine } & $7.0^{\mathrm{d}}$ & 0.0000575 & $0.61-5.16$ & $2.77-6.85$ & 6 \\
\hline & $7.5^{\mathrm{d}}$ & 0.000182 & $0.607-6.07$ & $4.14-16.4$ & 6 \\
\hline & $8.0^{\mathrm{d}}$ & 0.000724 & $0.607-6.07$ & $7.08-46.6$ & 6 \\
\hline \multirow[t]{6}{*}{ piperazine + piperazinium ion } & $6.7^{d}$ & e & $0.678-6.78$ & $10.8-82.9$ & 7 \\
\hline & $7.0^{d}$ & $\mathrm{f}$ & $0.585-5.85$ & $11.2-82.0$ & 7 \\
\hline & $7.3^{\mathrm{d}}$ & $\mathrm{g}$ & $0.56-4.76$ & $13.3-81.4$ & 6 \\
\hline & $7.6^{d}$ & $\mathrm{~h}$ & $0.594-5.94$ & $18.6-137$ & 7 \\
\hline & $7.9^{d}$ & $\mathrm{i}$ & $0.611-6.11$ & $22.3-178$ & 7 \\
\hline & $8.2^{\mathrm{d}}$ & $\mathrm{j}$ & $0.608-6.08$ & $35.3-292$ & 7 \\
\hline \multirow[t]{3}{*}{ 1-(2-hydroxyethyl)piperazine } & $7.2^{\mathrm{d}}$ & 0.00656 & $0.660-4.60$ & $8.90-32.0$ & 5 \\
\hline & $7.5^{d}$ & 0.0130 & $0.611-6.11$ & $9.70-64.4$ & 7 \\
\hline & $7.8^{\mathrm{d}}$ & 0.0256 & $0.628-6.28$ & $16.2-119$ & 7 \\
\hline \multirow[t]{3}{*}{ morpholine } & $6.0^{\mathrm{d}}$ & 0.00165 & $0.622-6.22$ & $2.96-11.3$ & 7 \\
\hline & $6.5^{\mathrm{d}}$ & 0.00522 & $0.630-4.42$ & $4.64-20.6$ & 5 \\
\hline & $7.0^{\mathrm{d}}$ & 0.0163 & $0.579-5.79$ & $9.61-63.2$ & 7 \\
\hline \multirow[t]{3}{*}{ 1-formylpiperazine } & 7.33 & 0.173 & $0.513-5.13$ & $16.0-128$ & 7 \\
\hline & 7.63 & 0.295 & $0.505-5.05$ & $17.1-156$ & 7 \\
\hline & 7.93 & 0.455 & $0.519-5.19$ & $22.4-188$ & 7 \\
\hline \multicolumn{6}{|c|}{${ }^{\mathrm{a}} \mathrm{In} 44 \mathrm{wt} \%$ ethanol-water, at $25.0{ }^{\circ} \mathrm{C}$, ionic strength $0.2 \mathrm{M}(\mathrm{KCl}) .{ }^{\mathrm{b}} \mathrm{Free}$ amine fraction. } \\
\hline \multicolumn{6}{|c|}{$\begin{array}{l}{ }^{\mathrm{c}} \text { Concentration of total amine (free base plus protonated forms). }{ }^{\mathrm{d}} \text { Carbonate buffer } 0.01 \mathrm{M} .{ }^{\mathrm{e}} \text { Free } \\
\text { piperazine and piperazinium ion fractions are } 0.00051 \text { and } 0.88543 \text {, respectively. }\end{array}$} \\
\hline \multicolumn{6}{|c|}{${ }^{\mathrm{f}}$ Free piperazine and piperazinium ion fractions are 0.001077 and 0.9383 , respectively. } \\
\hline \multicolumn{6}{|c|}{${ }^{\mathrm{g}}$ Free piperazine and piperazinium ion fractions are 0.002214 and 0.9796 , respectively. } \\
\hline \multicolumn{6}{|c|}{${ }^{h}$ Free piperazine and piperazinium ion fractions are 0.004478 and 0.9796 , respectively. } \\
\hline \multicolumn{6}{|c|}{${ }^{\mathrm{i}}$ Free piperazine and piperazinium ion fractions are 0.008965 and 0.9830 , respectively. } \\
\hline \multicolumn{6}{|c|}{${ }^{\mathrm{j}}$ Free piperazine and piperazinium ion fractions are 0.01780 and 0.9782 , respectively. } \\
\hline
\end{tabular}


Table 2. Experimental conditions and $k_{\text {obsd }}$ values for the aminolysis of bis(2,4-dinitrophenyl) carbonate $(5)^{\mathrm{a}}$

\begin{tabular}{|c|c|c|c|c|c|}
\hline Amine & $\mathbf{p H}$ & $\boldsymbol{F}_{\mathrm{N}}^{\mathbf{b}}$ & $103[N]_{\text {tot }} / \mathbf{M}^{\mathrm{c}}$ & $103 k_{\text {obsd }} / \mathrm{s}^{-1}$ & $\begin{array}{l}\text { No.of } \\
\text { runs }\end{array}$ \\
\hline \multirow[t]{3}{*}{ piperidine } & $6.5^{\mathrm{d}}$ & 0.0000182 & $0.710-7.10$ & $18.0-22.1$ & 7 \\
\hline & $6.8^{\mathrm{d}}$ & 0.0000363 & $0.710-7.10$ & $19.3-24.6$ & 6 \\
\hline & $7.0^{d}$ & 0.0000575 & $0.773-7.73$ & $20.2-28.7$ & 6 \\
\hline \multirow[t]{4}{*}{ piperazine + piperazinium ion } & $7.0^{d}$ & e & $0.669-6.69$ & $38.9-225$ & 6 \\
\hline & $7.4^{\mathrm{d}}$ & $\mathrm{f}$ & $0.690-6.90$ & $51.3-319$ & 6 \\
\hline & $7.6^{d}$ & $\mathrm{~g}$ & $2.75-6.89$ & $161-359$ & 4 \\
\hline & $7.8^{\mathrm{d}}$ & $\mathrm{h}$ & $0.673-6.73$ & $64.4-479$ & 5 \\
\hline \multirow[t]{3}{*}{ 1-(2-hydroxyethyl)piperazine } & $6.5^{\mathrm{d}}$ & 0.001317 & $0.790-5.50$ & $19.8-41.5$ & 5 \\
\hline & $6.8^{\mathrm{d}}$ & 0.00632 & $0.700-7.00$ & $23.4-61.8$ & 7 \\
\hline & $7.0^{d}$ & 0.00415 & $0.740-5.16$ & $28.1-70.5$ & 5 \\
\hline \multirow[t]{3}{*}{ morpholine } & $6.5^{\mathrm{d}}$ & 0.00522 & $0.690-6.90$ & $22.6-91.1$ & 7 \\
\hline & $6.8^{\mathrm{d}}$ & 0.01036 & $0.460-4.60$ & $19.4-120$ & 6 \\
\hline & $7.0^{d}$ & 0.01632 & $0.460-4.60$ & $28.3-187$ & 7 \\
\hline \multirow[t]{3}{*}{ 1-formylpiperazine } & $6.5^{\mathrm{d}}$ & 0.0321 & $0.960-8.13$ & $45.5-223$ & 6 \\
\hline & $6.8^{\mathrm{d}}$ & 0.0620 & $0.970-9.70$ & $47.3-400$ & 7 \\
\hline & $7.0^{d}$ & 0.0948 & $0.800-8.00$ & $74.2-527$ & 7 \\
\hline \multirow[t]{3}{*}{ piperazinium ion } & 5.07 & 0.33 & $0.700-5.98$ & $21.8-61.7$ & 6 \\
\hline & 5.37 & 0.50 & 0.710-4.99 & $25.1-81.5$ & 5 \\
\hline & 5.67 & 0.667 & $0.690-4.81$ & $25.6-95.2$ & 5 \\
\hline \multicolumn{6}{|c|}{${ }^{\mathrm{a}}$ In $44 \mathrm{wt} \%$ ethanol-water, at $25.0{ }^{\circ} \mathrm{C}$, ionic strength $0.2 \mathrm{M}(\mathrm{KCl}) .{ }^{\mathrm{b}}$ Free amine fraction. } \\
\hline \multicolumn{6}{|c|}{${ }^{\mathrm{c}}$ Concentration of total amine (free base plus protonated forms). ${ }^{\mathrm{d}}$ Carbonate buffer $0.01 \mathrm{M}$. } \\
\hline \multicolumn{6}{|c|}{${ }^{\mathrm{e}}$ Free piperazine and piperazinium ion fractions are 0.001077 and 0.9383 , respectively. } \\
\hline \multicolumn{6}{|c|}{${ }^{\mathrm{f}}$ Free piperazine and piperazinium ion fractions are 0.002804 and 0.9722 , respectively. } \\
\hline \multicolumn{6}{|c|}{${ }^{\mathrm{g}}$ Free piperazine and piperazinium ion fractions are 0.004478 and 0.9796 , respectively. } \\
\hline \multicolumn{6}{|c|}{${ }^{\mathrm{h}}$ Free piperazine and piperazinium ion fractions are 0.007120 and 0.9828 , respectively. } \\
\hline
\end{tabular}

Due to the fact that the reactions with piperazine were too fast at $\mathrm{pH}=\mathrm{p} K_{\mathrm{a}}$, these reactions were studied at $\mathrm{pH}$ 6.7-8.2, where a mixture of piperazine (6) and piperazinium ion (7) are present. In these cases the $k_{\mathrm{N}}$ values were obtained through Eqs 3 and 4 , where $k_{\text {Nobsd }}$ is a global nucleophilic rate constant (corresponding to the mixture of nucleophiles), $[\mathrm{N}]_{\text {tot }}$ is the total piperazine (species 6 and 7) concentration, $F_{6}$ and $F_{7}$ are their molar fractions, respectively, and $k_{6}$ and $k_{7}$ are their corresponding nucleophilic rate constants. ${ }^{8}$ The values of $k_{\text {Nobsd }}$ were obtained as the slopes of linear $k_{\text {obsd }}$ vs $[\mathrm{N}]_{\text {tot }}$ plots at constant $\mathrm{pH}$, according to eq 3 . The $k_{\mathrm{N}}$ values for the reactions of both carbonates with species 6 and 7 ( $k_{6}$ and $k_{7}$, respectively) were determined through Eq 4, as described. ${ }^{8}$ 


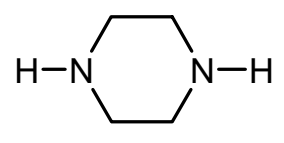

6

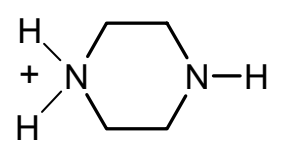

7

$$
\begin{aligned}
& k_{\text {obsd }}=\mathrm{k}_{0}+\mathrm{k}_{\mathrm{Nobs}}[\mathrm{N}]_{\mathrm{tot}}(3) \\
& k_{\text {Nobsd }}=F_{6} k_{6}+F_{7} k_{7}
\end{aligned}
$$

The values of $k_{\mathrm{N}}$ for the reactions of both substrates are shown in Table 3. These values, as well as those of the $\mathrm{p} K_{\mathrm{a}}$ of the conjugate acids of the amines, were statistically corrected with $q=2$ for piperazine and $p=2$ for the conjugate acids of the amines, except that for piperazinium ion with $p=4{ }^{8,9}$ With these corrected values, the Brønsted-type plots (shown in Figure 1) were obtained.

Table 3. Values of $\mathrm{p} K_{\mathrm{a}}$ for the conjugate acids of secondary alicyclic (SA) amines and $k_{\mathrm{N}}$ values for the reactions of SA amines with 4-nitrophenyl 2,4-dinitrophenyl carbonate (4) and bis(2,4dinitrophenyl) carbonate (5) ${ }^{\mathrm{a}}$

\begin{tabular}{llll}
\hline & \multicolumn{3}{l}{$\boldsymbol{k}_{\mathbf{N}} / \mathbf{s}^{-\mathbf{1}} \mathbf{M}^{-\mathbf{1}}$} \\
\cline { 4 - 4 } Amine & $\mathbf{p} \boldsymbol{K}_{\mathbf{a}}$ & $\mathbf{4}$ & $\mathbf{5}$ \\
\hline piperidine & 11.24 & $4720 \pm 60$ & $9800 \pm 600$ \\
piperazine & 9.94 & $600 \pm 40$ & $3700 \pm 400$ \\
1-(2-hydroxyethyl)piperazine & 9.38 & $370 \pm 5$ & $1230 \pm 50$ \\
morpholine & 8.78 & $325 \pm 5$ & $1060 \pm 40$ \\
1-formylpiperazine & 7.98 & $54 \pm 3$ & $330 \pm 20$ \\
piperazinium ion ( from $\mathrm{pH}=\mathrm{pKa})$ & 5.81 & & $25.7 \pm 0.6$ \\
piperazinium ion (from the mixture) & 5.81 & $11.5 \pm 0.5$ & $23.3 \pm 3$ \\
\hline
\end{tabular}

${ }^{\mathrm{a}}$ Both the $\mathrm{p} K_{\mathrm{a}}$ and $k_{\mathrm{N}}$ values were determined in $44 \mathrm{wt} \%$ ethanol-water, at $25.0{ }^{\circ} \mathrm{C}$, and an ionic strength of $0.2 \mathrm{M}(\mathrm{KCl})$. 


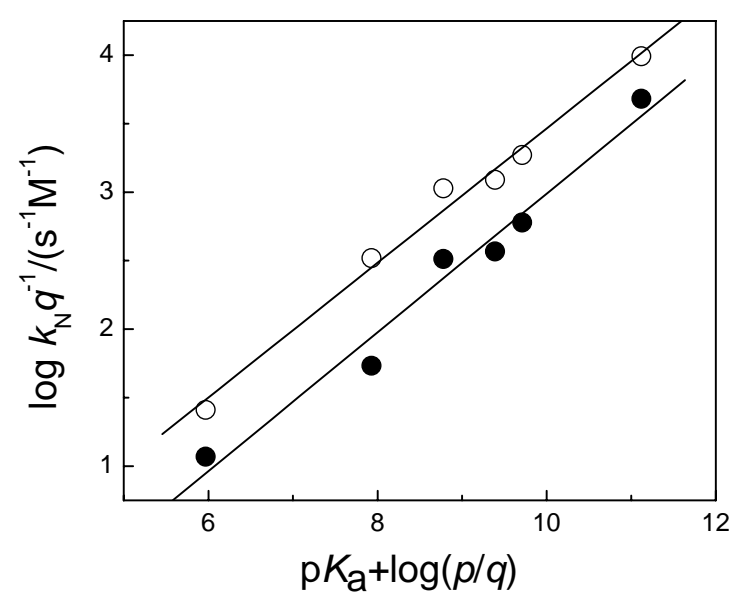

Figure 1. Brønsted-type plots (statistically corrected) for the reactions of SA amines with 4 (•) and 5 (o) in $44 \mathrm{wt} \%$ ethanol-water, at $25.0^{\circ} \mathrm{C}$, ionic strength $0.2 \mathrm{M}$.

Figure 1 shows the Brønsted-type plot for the reactions studied. These are linear with slopes $\beta=0.51$ and 0.48 for the reactions of 4 and 5 , respectively. These $\beta$ values suggest a concerted mechanism (Scheme 1), since these slope values are in accordance with those found for the concerted aminolysis of similar compounds. Examples of these are the aminolyses (anilines and quinuclidines) of carbonates 1-3, with $\beta$ values in the range $0.4-0.7$, some of them in water ${ }^{5}$ and others in aqueous ethanol. ${ }^{6,7}$

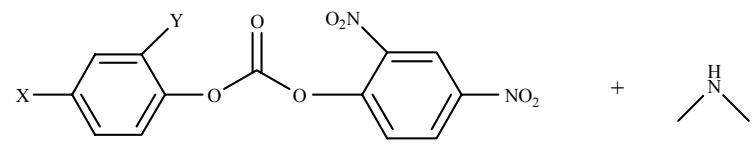

\section{Scheme 1}

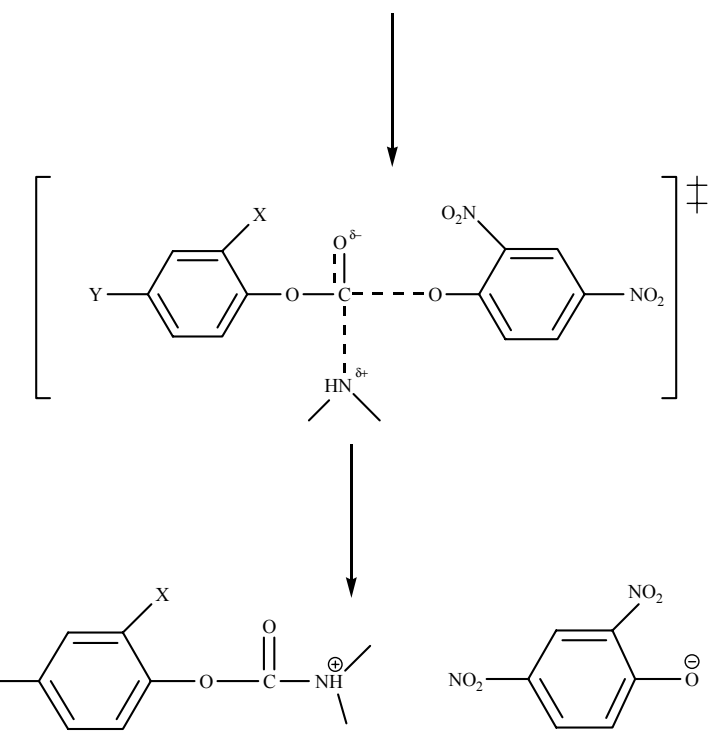


Another reason to conclude that the mechanisms for both reactions are concerted is the following: the reactions of SA amines with 4-methylphenyl and 4-chlorophenyl 2,4dinitrophenyl carbonates ( 2 and 3, respectively) have been described as concerted. ${ }^{6,7}$ This means that the putative zwitterionic tetrahedral intermediate $\left(\mathrm{T}^{ \pm}\right)$formed is extremely unstable. Therefore, since 4-nitrophenoxy and 2,4-dinitrophenoxy are even more destabilizing nonleaving groups than 4-methylphenoxy and 4-chlorophenoxy, it is reasonable that the putative $\mathrm{T}^{ \pm}$ intermediates formed in the title reactions would be even more destabilized, leading to a concerted mechanism.

It is known that the $\beta$ value alone is not enough to conclude that a mechanism is concerted. It is also necessary to make sure that the expected $\mathrm{p} K_{\mathrm{a}}$ value at the center of the Brønsted curvature $\left(\mathrm{p} K_{\mathrm{a}}{ }^{0}\right)$ for a hypothetical stepwise mechanism is within the $\mathrm{p} K_{\mathrm{a}}$ range used. ${ }^{10,11}$ The expected $\mathrm{pK}_{\mathrm{a}}{ }^{0}$ value for the title reactions if they were stepwise can be estimated as follows.

For the pyridinolysis of 4-methylphenyl and 4-chlorophenyl 4-nitrophenyl carbonates biphasic nonlinear (two linear regions and a curvature in between) downward Brønsted plots with $\mathrm{pK}_{\mathrm{a}}{ }^{0}$ values of $c a .9 .5$ were found (unpublished work). For the SA aminolysis of the same substrates biphasic plots were also obtained, with $\mathrm{pK}_{\mathrm{a}}{ }^{0}$ values of $c a \cdot 10.5$. $^{6,12}$ Therefore, the change from pyridines to SA amines increases the $\mathrm{p} K_{\mathrm{a}}{ }^{0}$ value by ca. one $\mathrm{p} K_{\mathrm{a}}$ unit. This has been explained by the superior leaving ability from the intermediate $\mathrm{T}^{ \pm}$of SA amines compared with isobasic pyridines. $^{8 \mathrm{~b}}$

For the pyridinolysis of carbonates 2 and 3, nonlinear biphasic Brønsted plots were found, with $\mathrm{pK}_{\mathrm{a}}{ }^{0}=7.5$ and 7.2, respectively (unpublished data). Therefore, if the SA aminolysis of these substrates were stepwise, $\mathrm{pK}_{\mathrm{a}}{ }^{0}$ values of ca. 8.2-8.5 would be expected. The absence of a break at these expected values (see Figure 1) confirm the concerted mechanisms (Scheme 1) for the reactions under investigation.

In order to evaluate the influence of the non-leaving group on the kinetics of the aminolysis reactions of aryl 2,4-dinitrophenyl carbonates, a multiparametric study was carried out. With the experimental $k_{\mathrm{N}}$ values obtained in this work and those for the SA aminolysis of carbonates 2 and $3,{ }^{6,7}$ and the corresponding $\mathrm{p} K_{\mathrm{a}}$ values, Eq 5 was obtained $\left(\mathrm{n}=24, \mathrm{R}^{2}=0.958\right)$. In this equation $\mathrm{p} K_{\mathrm{N}}$ and $\mathrm{p} K_{\mathrm{nlg}}$ are the $\mathrm{p} K_{\mathrm{a}}$ of the conjugated acids of the nucleophiles and non-leaving groups, respectively.

$$
\log k_{\mathrm{N}}=(-0.22 \pm 0.26)+(0.45 \pm 0.03) \mathrm{p} K_{\mathrm{N}}-(0.20 \pm 0.01) \mathrm{p} K_{\mathrm{nlg}}
$$

Figure 2 shows a logarithmic plot of the experimental $k_{\mathrm{N}}$ values vs those calculated using Eq 5. 


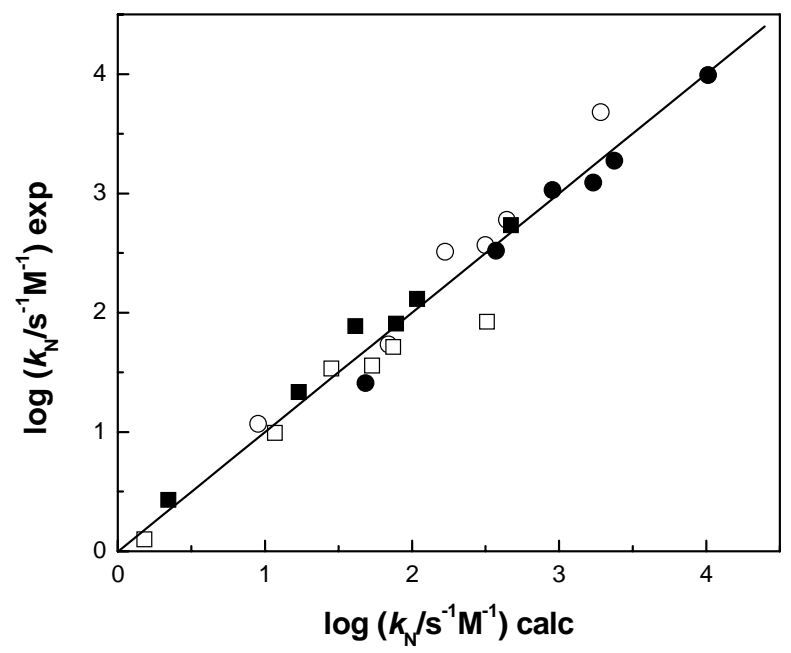

Figure 2. Logarithmic plot of the experimental $k_{\mathrm{N}}$ values vs those calculated (through eq 5) for the reactions of SA amines with 2 ( $\square$, ref 6), 3 ( $\bullet$, ref 7), 4 (०, this work) and $\mathbf{5}(\bullet$, this work), in 44 wt $\%$ ethanol-water, at $25.0{ }^{\circ} \mathrm{C}$ and ionic strength $0.2 \mathrm{M}$.

The sensitivities of the pKa of the amine $\left(\beta_{\mathrm{N}}\right)$, leaving group $\left(\beta_{\mathrm{lg}}\right)$ and non-leaving group $\left(\beta_{\mathrm{nlg}}\right)$ can be related through Eq $6,{ }^{13}$ from which a value of $\beta_{\mathrm{lg}}=-0.25$ can be deduced.

$$
\beta_{\mathrm{N}}=\beta_{\mathrm{lg}}+\beta_{\mathrm{nlg}}
$$

The similar sensitivities of the coefficients for the leaving and non-leaving groups should be due to the fact that probably both groups belong to the same family (phenoxy). A similar result was found for the phenolysis reactions of a series of diaryl carbonates. ${ }^{13}$

\section{Experimental Section}

General Procedures. The SA amines were purified as reported. ${ }^{8 a}$ Carbonate 4 was synthesized by the reaction of 2,4-dinitrophenol with 4-nitrophenyl chloroformate, following the general method. ${ }^{3,6,12}$ Carbonate 5 was synthesized by the reaction of phosgene with 2,4-dinitrophenol, in accordance with the method described. ${ }^{14}$

Kinetic measurements. The reactions were followed spectrophotometrically $(210-500 \mathrm{~nm})$ by means of a diode array instrument. The rate constants were measured following the absorbance change due to the appearance of the 2,4-dinitrophenoxide ion at $360 \mathrm{~nm}$. The reactions were investigated in $44 \mathrm{wt} \%$ ethanol-water solutions, at $25.0 \pm 0.1^{\circ} \mathrm{C}$, and an ionic strength of $0.2 \mathrm{M}$ 
(maintained with $\mathrm{KCl}$ ). In all reactions the concentration of total amine (free amine plus its protonated form) was much greater (at least 10-fold) than that of the substrate.

In all cases, pseudo-first-order rate coefficients $\left(k_{\text {obsd }}\right)$ were obtained by means of the kinetic software of the spectrophotometer. All reactions were carried out in duplicate and the values of kobsd agreed within $5 \%$.

Product studies. One of the products in the aminolysis of both substrates was identified as 2,4dinitrophenoxide. The identification was carried out by comparison of the UV-vis spectra at the end of these reactions with that of an authentic sample 2,4-dinitrophenol, under the same reaction conditions.

\section{Acknowledgements}

The financial assistance provided by MECESUP of Chile (Project MECESUP UCH0601) and FONDECYT of Chile (Project 1060593), is gratefully acknowledged.

\section{References and Notes}

1. (a) Sklavounos, C.; Goldman, I. M.; Kuhla, D. E. J. Org. Chem. 1980, 45, 4239. (b) Grace, M. E.; Loosemore, M. J.; Semmel, M. L.; Pratt, R. F. J. Am. Chem. Soc. 1980, 102, 6784. (c) Fife, T. H.; Hutchins, J. E. C. J. Am. Chem. Soc. 1981, 103, 4194. (d) Koh, H. J.; Lee, J. W.; Lee, H. W.; Lee, I. Can. J. Chem. 1998, 76, 710. (e) Tundo, P.; Rossi, L.; Loris, A. J. Org. Chem. 2005, 70, 2219.

2. (a) Bond, P. M.; Moodie, R. B. J. Chem. Soc., Perkin Trans. 2 1976, 679. (b) Castro, E. A.; Gil, F. J. J. Am. Chem. Soc. 1977, 99, 7611. (c) Castro, E. A.; Freudenberg, M. J. Org. Chem. 1980, 45, 906. (d) Castro, E. A.; Ibañez, F.; Lagos, S.; Schick, M.; Santos, J. G. J. Org. Chem. 1992, 57, 2694.

3. Gresser, M. J.; Jencks, W. P. J. Am. Chem. Soc. 1977, 99, 6963.

4. (a) Um, I-H; Park, H-R.; Kim, E-Y. Bull. Korean Chem. Soc. 2003, 24, 1251. (b) Um, IH; Kim, E-Y.; Park, H-R.; Jeon, S-E. J. Org. Chem. 2006, 71, 2302.

5. Castro, E. A.; Campodónico, P. R.; Contreras, R.; Fuentealba, P.; Santos, J. G; Leis, J. R.; García-Río, L.; Saez, J. A.; Domingo, L. R. Tetrahedron 2006, 62, 2555.

6. Castro, E. A.; Andujar, M.; Campodónico, P.; Santos, J. G. Int. J. Chem. Kinet. 2002, 34, 309.

7. Castro, E. A.; Campodónico, P.; Toro, A.; Santos, J. G. J. Org. Chem. 2003, 68, 5930.

8. (a) Castro, E. A.; Ureta, C. J. Org. Chem. 1989, 54, 2153. (b) Castro, E. A.; Ureta, C. J. Chem. Soc., Perkin Trans. 2 1991, 63.

9. Bell, R. P. “The Proton in Chemistry Methuen” London, 1959; p. 159. 
10. (a) Chrystiuk, E.; Williams A. J. Am. Chem. Soc. 1987, 109, 3040. (b) Williams, A. Acc. Chem. Res. 1989, 22, 387.

11. Williams, A. "Free Energy Relationships in Organic and Bio-Organic Chemistry" The Royal Society of Chemistry: Cambridge, 2003; pp 171-172.

12. Castro, E. A.; Andujar, M.; Toro, A.; Santos, J. G. J. Org. Chem. 2003, 68, 3608.

13. Castro, E. A.; Pavez, P.; Santos, J. G. J. Org. Chem. 2002, 67, 4494.

14. El Seoud, O. E.; El Seoud, M. I.; Farah, J. P. S. J. Org. Chem. 1997,62, 5928. 